\title{
One-dimensional morphodynamic model coupling open-channel flow and turbidity current in reservoir
}

\author{
Zenghui Wang ${ }^{1}$, Junqiang Xia ${ }^{1 *}$, Shanshan Deng ${ }^{1}$, Junhua Zhang ${ }^{2}$, Tao $\mathrm{Li}^{2}$ \\ ${ }^{1}$ State Key Laboratory of Water Resources and Hydropower Engineering Science, Wuhan University, 430072 Wuhan, China. \\ 2 Yellow River Institute of Hydraulic Research, YRCC, 450003 Zhengzhou, China. \\ ${ }^{*}$ Corresponding author. E-mail: xiajq@whu.edu.cn
}

\begin{abstract}
Traditional depth-averaged morphodynamic models for turbidity currents usually focus on the propagation of currents after plunging. However, owing to the unsteady characteristic of the plunge point locations and the tough conditions of field measurement within the plunge zone in a reservoir, it is difficult in practice to directly provide upstream boundary conditions for these models. A one-dimensional (1D) morphodynamic model coupling open-channel flow and turbidity current in a reservoir was proposed to simulate the whole processes of turbidity current evolution, from formation and propagation to recession. The 1D governing equations adopted are applicable to open-channel flows and turbidity currents over a mobile bed with irregular cross-section geometry. The coupled solution is obtained by a two-step calculation mode which alternates the calculations of open-channel flow and turbidity current, and a plunge criterion is used to determine the location of the upstream boundary for the turbidity current, and to specify the corresponding boundary conditions. This calculation mode leads to consecutive predictions of the hydrodynamic and morphological factors, from the open-channel reach to the turbidity current reach. Turbidity current events in two laboratory experiments with different set-ups were used to test the capabilities of the proposed model, with the effect of free-surface gradient also being investigated. A field-scale application of the coupled model was conducted to simulate two turbidity current events occurring in the Sanmenxia Reservoir, and the method for calculating the limiting height of aspiration was adopted to estimate the outflow discharge after the turbidity currents arrived in front of the dam. The predicted plunge locations and arrival times at different cross-sections were in agreement with the measurements. Moreover, the calculated interface evolution processes and the sediment delivery ratios also agreed generally with the observed results. Therefore, the 1D morphodynamic model proposed herein can help to select the design capacity of the outlets, and optimize the procedure for sediment release in reservoirs.
\end{abstract}

Keywords: Turbidity current; Open-channel flow; Coupled solution; Morphodynamic model; Plunge point; Reservoir.

\section{INTRODUCTION}

Turbidity current is a type of gravity current, driven by the horizontal difference in density from ambient fluid, as a result of dissolved components or dissoluble particles. Sedimentladen turbidity currents in reservoirs play an important role in erosion and deposition processes (Morris and Fan, 1998; Zhang and Xie, 1993). Inadequate considerations for turbidity currents in the design or operation of a reservoir can reduce its functionality and even shorten its lifespan. For example, an insufficient discharge capacity or delayed opening of bottom outlets in a reservoir can lead to the formation of a muddy lake, which interrupts diversion and traps excessive silt; turbidity currents deposit at the confluence of the reservoir pool and its tributary, which usually forms a sandbar and blocks part of the beneficial storage capacity (Fan and Morris, 1992).

Shallow water equations (SWEs) are commonly adopted to develop mathematical models for turbidity currents. On the assumption that the value of the Reynolds number is large enough and the value of the Froude number at the current front is constant, an analytical solution can be derived to describe the self-similar propagation phase, or equivalently the near-field close to the current head (Chen, 1980; Hoult, 1972; Huppert, 2006). Ruo and Chen (2007) proposed the modified shallow water equations, including the resistance force from the ambient water in terms of dynamic pressure, so that it was unnecessary to specify the Froude number at the front as a boundary condition, and then obtained the approximate solutions in the far- and near-field regions. Previous analytical solutions are applicable to calculations of turbidity current propagation in a regular geometric domain with specific upstream conditions, i.e., the "constant volume" release or the "constant flux" release. Other influencing factors are not accounted for, including the sediment exchange with the bed and the water entrainment at the interface between the current and the ambient water, and it is impossible to obtain analytical solutions to the SWEs with these factors. Thus more efforts have been made to investigate the turbidity currents using numerical models with different levels of resolution.

Parker et al. (1986) developed a three-equation model considering sediment exchange with the bed and water entrainment from the upper layer, but the feedback impacts on the momentum transfer of turbidity current were ignored in the model, and the process of bed deformation was also not considered. Hu and Cao (2009) developed a depth-averaged model for turbidity currents over erodible beds, based on rigorous conservative laws coupling the processes of flow-sediment transport and bed evolution. The proposed model was applied to simulate turbidity current events occurring in the Xiaolangdi Reservoir ( $\mathrm{Hu}$ et al., 2012). As pointed out by Cao et al. (2015), models of this type are restricted to predicting the propagation of turbidity currents after their formation. Therefore, the application of these models usually focused on typical case studies with specified inflow conditions (e.g., Bradford and Katopodes, 1999a, b; Sequeiros et al., 2009), or depended on observed data downstream of the plunge point for reservoir turbidity currents (e.g., $\mathrm{Hu}$ et al., 2012). However, in-situ measurements around the plunge location in a turbidity current event are rare owing to the 
unsteady characteristic. Cao et al. (2015) recently developed a double layer-averaged model to predict the formation process, and conducted a whole-process simulation of reservoir turbidity current using this model. Another model category for turbidity currents includes vertical two-dimensional (2D) and full threedimensional (3D) models (Bournet et al., 1999; Cantero et al., 2009; De Cesare et al., 2006; Huang et al., 2008). The governing equations adopted are Navier-Stokes equations, with no special attention required for different treatments for subaerial and subaqueous flows. However, depth-resolving models are computationally expensive, and the majority of applications are restricted to laboratory-scale simulations or simplified situations with horizontal free surfaces and fixed beds.

Instead of using a double layer-averaged model to achieve automatic transition from open-channel flow to turbidity current, a plunge criterion based on the previous study (Xia et al., 2016) is adopted in the current study to determine the plunge point location, with a two-step calculation mode being proposed to couple the open-channel flow and turbidity current processes. Firstly the one-dimensional hydrodynamic equations incorporating the sediment transport and bed evolution are derived, in which the term representing the impact from the pressure of the upper clear water is reserved. Then the numerical solution based on the two-step calculation mode is illustrated in detail. Laboratory experiments with different types of source conditions, covering the sustained inflow (Lee and $\mathrm{Yu}$, 1997) and instantaneous release (Bonnecaze et al., 1993), were simulated to test the model's ability to predict the hydrodynamics and the resulting sedimentation. Finally, the model was applied to simulate two typical turbidity current events occurring in the Sanmenxia Reservoir, Yellow River, China. The entire processes of these two events were predicted in detail and compared with the measurements, and concerning factors for reservoir sedimentation management were also predicted, including arrival time and sediment delivery ratio.

The model presented in this paper differs from previous turbidity current models in that the standard one-dimensional section-averaged equations are generalized to describe openchannel flows as well as turbidity currents, for the case of a channel with a variable cross-section. The solution procedure coupling open-channel flows and turbidity currents facilitate a direct investigation into the relationship between the inflow conditions and the formation and evolution of turbidity currents. Numerical simulations for the Sanmenxia Reservoir also provide a new insight into the efficiency of turbidity current venting as a sediment management strategy.

\section{FRAMEWORK OF MATHEMATICAL MODEL Governing equations}

Previous 1D governing equations of turbidity currents are mostly developed for rectangular cross-sectional geometry (Hu and Cao, 2009; Pantin, 1979; Parker et al., 1986). For channels with irregular cross-sections, 1D hydrodynamic equations can be derived in the same way as the St Venant equations for sediment-laden flows are obtained (Wu and Wang, 2007; Zhang and Duan, 2011), with a careful treatment of the section integral term of hydrostatic pressure. As shown in Figure 1, the process of turbid flow is divided into two regimes, including the open-channel flow upstream of the plunge point and the turbidity current downstream. Attaching the $x$ axis along the bed, the section-averaged equations of mass and momentum conservation for turbidity current are written in the following form:

$$
\begin{aligned}
& \frac{\partial\left(\rho_{m} A\right)}{\partial t}+\frac{\partial\left(\rho_{m} Q\right)}{\partial x}=-\rho_{b} \frac{\partial\left(A_{b}\right)}{\partial t}+\rho_{c} B_{I} e_{c} U \\
& \frac{\partial\left(\rho_{m} Q\right)}{\partial t}+\frac{\partial}{\partial x}\left(\frac{\rho_{m} Q^{2}}{A}\right)+\frac{\partial \int_{0}^{h_{m}} p_{z} B_{z} d z}{\partial x}= \\
& \rho_{m} g A S_{b}-\rho_{m} g A S_{f}^{\prime}+\int_{0}^{h_{m}} p_{z} \frac{\partial B_{z}}{\partial x} d z+\rho_{c} g h_{c} B_{I} \frac{\partial h_{m}}{\partial x}
\end{aligned}
$$

where $\rho_{c}$ and $\rho_{m}$ are densities of the clear water and the watersediment mixture in the turbidity current, respectively; $A$ and $Q$ represent the wetted cross-sectional area and the discharge, respectively; $\rho_{b}$ is the density of the saturated bed; $A_{b}$ is the cross-sectional area of the bed above a reference datum; $h_{m}$ and $h_{c}$ are the depths of the turbidity current and upper clear water, respectively; $p_{z}$ and $B_{z}$ represent the pressure and width of the cross-section at a given $\mathrm{z}$ coordinate; $g$ is the gravitational acceleration; $S_{b}$ is the bed slope; $S_{f}^{\prime}$ denotes the composite friction slope; $B_{I}$ denotes the width of the interface between the clear-water layer and the turbidity current layer; $e_{c}$ denotes the water entrainment coefficient; and $U$ denotes the sectionaveraged flow velocity. The third term on the right-hand side (RHS) of Eq. (2) denotes the pressure of the channel wall. There are no section-averaged variables in the last term because it denotes the $x$ component of the pressure at the interface. Eq. (2) is similar to the generalized momentum equation for 1D turbid open channel flow by Xie (1990), except for the last term

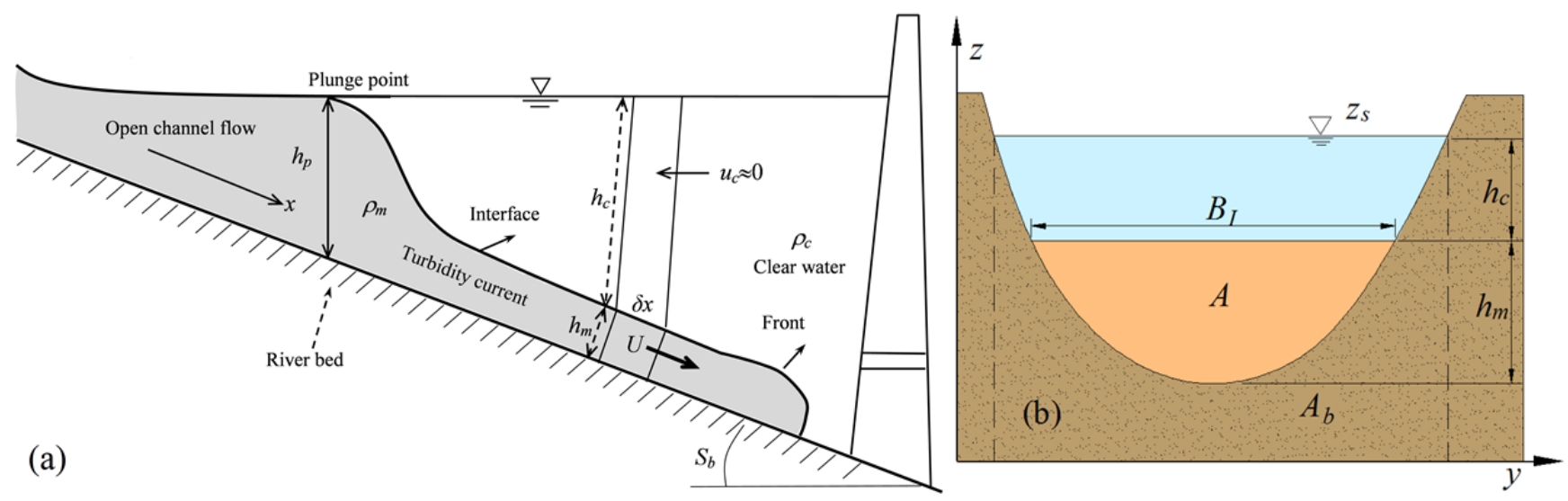

Fig. 1. Sketch of turbidity current propagation: (a) longitudinal profile; (b) cross-section. 
being additionally introduced. For open channel flows, the interface is between the air and the flow $\left(h_{\mathrm{c}}=0\right)$, the additional term becomes zero automatically. In this sense, this additional term makes Eq. (2) a more generalized momentum equation compared to that of Xie (1990), as it applies to both subaerial and subaqueous flows.

According to Leibnitz's rule, the third term on the left-hand side (LHS) of Eq. (2) can be expanded as:

$$
\begin{gathered}
\frac{\partial \int_{0}^{h_{m}} p_{z} B_{z} d z}{\partial x}=\int_{0}^{h_{m}} \frac{\partial\left(p_{z} B_{z}\right)}{\partial x} d z+p_{I} B_{I} \frac{\partial h_{m}}{\partial x}= \\
\int_{0}^{h_{m}} p_{z} \frac{\partial B_{z}}{\partial x} d z+\int_{0}^{h_{m}} B_{z} \frac{\partial p_{z}}{\partial x} d z+p_{I} B_{I} \frac{\partial h_{m}}{\partial x}
\end{gathered}
$$

where $p_{I}$ is the pressure at the interface between clear and turbid water. Using this expansion together with the hypothesis of static pressure $p_{z}=\rho_{c} g h_{c}+\rho_{m} g\left(h_{m}-z\right)$ and the relationship $h_{c}=z_{s}-z_{b}-h_{m} \quad\left(z_{s}\right.$ is the free-surface elevation and $z_{b}$ bed elevation), the momentum conservative equation can be rewritten as

$$
\begin{aligned}
& \frac{\partial\left(\rho_{m} Q\right)}{\partial t}+\frac{\partial}{\partial x}\left(\frac{\rho_{m} Q^{2}}{A}\right)= \\
& \rho_{m} g^{\prime} A S_{b}-\rho_{m} g A S_{f}^{\prime}-\rho_{c} g A \frac{\partial z_{s}}{\partial x}-\rho_{m} g^{\prime} A \frac{\partial h_{m}}{\partial x}-g h_{c t} A \frac{\partial \rho_{m}}{\partial x}
\end{aligned}
$$

where $g^{\prime}=\left(\rho_{m}-\rho_{c}\right) g / \rho_{m}$ is the reduced gravitational acceleration, and $h_{c t}=\left[\int_{0}^{h_{m}} B_{z}\left(h_{m}-z\right) d z\right] / A$ denotes the centroid of the cross-section of the current. The third term on the RHS of Eq. (4) represents the impact of the upper clear water on the momentum transfer in the turbidity current. This term vanishes in Eq. (4) when adopting the still ambient water assumption that implies the gradient of the free surface is zero. When $h_{c}=$ $0, z_{\mathrm{s}}$ equals $z_{b}+h_{m}$, Eq. (4) can be transferred to the ordinary momentum equation of turbid open-channel flow.

The equations for sediment transport and bed deformation are similar to the ones used in the common morphodynamic model for open-channel flows, which can be written as:

$$
\begin{aligned}
& \frac{\partial\left(A S_{v}\right)}{\partial t}+\frac{\partial\left(Q S_{v}\right)}{\partial x}=B_{I}(E-D) \\
& \frac{\partial A_{b}}{\partial t}=\frac{B_{I}(D-E)}{1-p}
\end{aligned}
$$

where $S_{v}$ is the volumetric sediment concentration; $E$ and $D$ are the sediment entrainment and deposition fluxes, respectively; and $p$ is the porosity of bed material. If non-uniform sediment is considered, the sediment transport and bed evolution equations can be written in the form of Eqs. (5) and (6) for each fraction, and an extra procedure to compute the adjustment of bed material composition needs to be included (Xia et al, 2010).

In order to conduct a numerical solution using conservative variables of $A, Q$ and $A S_{v}, \rho_{m}$ needs to be removed from the LHS of Eqs. (1) and (4). Considering Eqs. (1), (5) and (6) with the relationships $\rho_{m}=\rho_{c}\left(1-S_{v}\right)+\rho_{s} S_{v} \quad$ and $\rho_{b}=\rho_{c} p+\rho_{s}(1-p) \quad\left(\rho_{s}\right.$ is the density of sediment particles $)$, the continuity equation finally turns into: $\frac{\partial A}{\partial t}+\frac{\partial Q}{\partial x}=\frac{B_{I}(E-D)}{1-p}+B_{I} e_{c} U$

By expanding the LHS of Eq. (4) and then correlating it with Eqs. (5) and (7), the momentum equation can be re-written as:

$$
\begin{aligned}
& \frac{\partial Q}{\partial t}+\frac{\partial}{\partial x}\left(\frac{Q^{2}}{A}\right)=-\frac{\rho_{b}-\rho_{m}}{\rho_{m}(1-p)} B_{I} U(E-D)+\frac{\rho_{m}-\rho_{c}}{\rho_{m}} B_{I} e_{c} U^{2} \\
& +g^{\prime} A S_{b}-g A S_{f}^{\prime}-g A \frac{\rho_{c}}{\rho_{m}} \frac{\partial z_{s}}{\partial x}-g^{\prime} A \frac{\partial h_{m}}{\partial x}-g h_{c t} \frac{A}{\rho_{m}} \frac{\partial \rho_{m}}{\partial x}
\end{aligned}
$$

Therefore, the governing equations of the proposed model of turbidity currents consist of Eqs. (5) - (8). The two terms on the RHS of Eq. (7) account for the effects of bed evolution and water entrainment on the mass conservation of the watersediment mixture. The first two terms on the RHS of Eq. (8) represent the momentum transfer owing to sediment exchange between the turbidity current and the mobile bed, and the water entrainment from the upper clear-water layer. The appearance of the fifth term provides more accurate quantization to the effect of the pressure of upper clear-water layer, compared to the traditional single layer models. The last term on the RHS of Eq. (8) represents the effect of spatial variation in sediment concentration on the momentum conservation. In previous models for rectangular cross-sectional geometry, this term can be combined with the penult term in Eq. (8) to form a pressure gradient term, but in models for irregular cross-sectional geometry it needs to be expressed explicitly.

\section{Empirical closure relationships}

The sediment entrainment flux $E$ and deposition flux $D$ can be expressed as:

$$
E=\alpha \omega S_{v}^{*}, D=\alpha \omega S_{v}
$$

where $\omega$ is the settling velocity of sediment particles in turbid water; $S_{v}^{*}$ is the volumetric sediment transport capacity; $\alpha=$ $0.001 / \omega^{k}$ is the recovery saturation coefficient, and $k=0.3$ when $S_{v}>S_{v}^{*}$, otherwise $k=0.7$ (Xia et al, 2010). A formula proposed by Zhang et al. (2002) is used to determine the volumetric sediment transport capacity, which is given as:

$S_{v}^{*}=\frac{2.5}{\rho_{s}}\left[\frac{\left(0.0022+S_{v}\right) U^{3}}{\kappa \frac{\rho_{s}-\rho_{m}}{\rho_{m}} g h_{m} \omega} \ln \left(\frac{h_{m}}{6 D_{50}}\right)\right]^{0.62}$

where $D_{50}$ is the median grain size and $\kappa$ is the Von Karman constant. This empirical formula is recommended in this study because it was calibrated with a lot of data from both flume experiments and field measurements in the Yellow River.

The water entrainment coefficient is calculated by (Parker et al., 1987):

$e_{c}=\frac{0.00153}{0.0204+R i}$

where $R i=g^{\prime} h_{m} / U^{2}$ is the Richardson number. 
The friction source term $g A S_{f}^{\prime}$ in Eq. (8) is decomposed into the open-channel friction part and the interface friction part,

$g A S_{f}^{\prime}=g A S_{f}+\frac{f}{8} U^{2} B_{I}$

where $f$ is the friction coefficient on the interface. The friction slope $S_{f}$ is calculated in the same way as in the open-channel flow, i.e., $S_{f}=Q|Q| / K^{2}, K=A R^{2 / 3} / n$, where $R$ is the hydraulic radius and $n$ is the Manning's roughness coefficient. The form of $S_{f}$ can lead to an extremely large friction term, where the current depth is very small, especially at the wetting and drying fronts. This large friction term can even reverse the flow direction and cause further computational instability (Tan, 1992). In order to avoid this situation, shear stress $\tau_{b}=c_{D} \rho_{m} U^{2}$ ( $c_{D}$ is the bed drag coefficient) is used to calculate the openchannel friction part when the thickness of the turbidity current is smaller than a specified threshold.

\section{Numerical method}

To illustrate the finite volume method used in the numerical solution, Eqs. (5), (7) and (8) are rearranged as the following vector form:

$$
\frac{\partial \mathbf{U}}{\partial t}+\frac{\partial \mathbf{F}}{\partial x}=\mathbf{S}
$$

where

$$
\begin{aligned}
& \mathbf{U}=\left[\begin{array}{c}
A \\
Q \\
A S_{v}
\end{array}\right], \mathbf{F}=\left[\begin{array}{c}
Q \\
Q^{2} / A \\
Q S_{v}
\end{array}\right], \mathbf{S}=\left[\begin{array}{c}
B_{I}(E-D) /(1-p)+B_{I} e_{c} U \\
M_{0} \\
B_{I}(E-D)
\end{array}\right] \\
& M_{0}=-\frac{\rho_{b}-\rho_{m}}{\rho_{m}(1-p)} B_{I} U(E-D)+\frac{\rho_{m}-\rho_{c}}{\rho_{m}} B_{I} e_{c} U^{2}+g^{\prime} A S_{b} \\
& -g A S_{f}^{\prime}-g A \frac{\rho_{c}}{\rho_{m}} \frac{\partial z_{s}}{\partial x}-g^{\prime} A \frac{\partial h_{m}}{\partial x}-g h_{c t} \frac{A}{\rho_{m}} \frac{\partial \rho_{m}}{\partial x}
\end{aligned}
$$

Eq. (13) is discretized explicitly as:

$$
\mathbf{U}_{i}^{m+1}=\mathbf{U}_{i}^{m}-\frac{\Delta t}{\Delta x}\left(\mathbf{F}_{i+1 / 2}^{m}-\mathbf{F}_{i-1 / 2}^{m}\right)+\Delta t \mathbf{S}_{i}^{m}
$$

where $i$ is the spatial node index; $m$ is the time step index; $\mathbf{F}_{i+1 / 2}^{m}$ is the numerical flux through the interface of two adjacent sections; and $\Delta t$ and $\Delta x$ are time and spatial steps, respectively.

The Total Variation Diminishing (TVD) version of the Weight Average Flux (WAF) scheme (Toro, 2009) is used to determine the numerical flux $\mathbf{F}_{i+1 / 2}^{m}$ at the interface. The WAF scheme has second-order accuracy in space, with the Van Leer limiter function being used to avoid spurious numerical oscillations. The HLLC Riemann solver is used to solve the local Riemann problem in the current study. Note that the second component of $\mathbf{F}$ only contains the convective term, so Eq. (13) is not written in a conserved form, and the homogeneous version of Eq. (13) does not comprise the common Riemann problem in the study of shallow water equations. However, the schemes based on the Riemann solver can still be used to evaluate the flux approximately in practice. For example, Zhang and Duan (2011) adopted the Roe scheme to simulate the routing of $1 \mathrm{D}$ unsteady flow over mobile beds.

The gradient term $\partial \rho_{m} / \partial x$ in the source vector $\mathbf{S}_{i}^{m}$ is discretized with the central difference method. The gradient terms $\partial h_{m} / \partial x$ and $\partial z_{s} / \partial x$ are discretized as the weighted average of upwind and downwind differences, choosing the weighting factors based on Courant number (Ying et al., 2004), i.e.,

$$
\frac{\partial z_{s}}{\partial x}=w_{1} \frac{z_{s, i+1}^{m}-z_{s, i}^{m}}{x_{i+1}-x_{i}}+w_{2} \frac{z_{s, i}^{m}-z_{s, i-1}^{m}}{x_{i}-x_{i-1}}
$$

where

$$
\begin{aligned}
& w_{1}=1-\frac{\Delta t}{2} \frac{U_{i}^{m}+U_{i+1}^{m}}{x_{i+1}-x_{i}}, w_{2}=\frac{\Delta t}{2} \frac{U_{i-1}^{m}+U_{i}^{m}}{x_{i}-x_{i-1}} \text { if } Q \geq 0 \\
& w_{1}=\frac{\Delta t}{2} \frac{U_{i}^{m}+U_{i+1}^{m}}{x_{i+1}-x_{i}}, w_{2}=1-\frac{\Delta t}{2} \frac{U_{i-1}^{m}+U_{i}^{m}}{x_{i}-x_{i-1}} \text { if } Q<0
\end{aligned}
$$

After updating $\mathbf{U}$, the bed evolution equation is discretized as:

$$
A_{b, i}^{m+1}=A_{b, i}^{m}+\Delta t \frac{\left[B_{I}(E-D)\right]_{i}^{m}}{1-p}
$$

The propagation of a turbidity current front is analogous to surge propagation over an initial dry bed. So the wave speed estimation in the HLLC Riemann solver at the interface between a wet and a dry cell needs to be modified according to Toro (2001), and a suitable small depth $\varepsilon$ is defined in order to differentiate between dry and wet cells, and to ensure that the current front does not propagate at an artificially high speed. Note the gravitational acceleration $g$ must be replaced with $g^{\prime}$ when estimating the wave speed. It is also noteworthy that the terms related to water entrainment in the continuity and momentum equations should be set to zero if the interface between the clear water and turbidity current layers rises to the elevation of free surface.

\section{Coupling open-channel flow and turbidity current}

Most existing depth-averaged models for turbidity currents can only simulate their propagation after formation, and the observed data somewhere downstream of the plunge point need to be input in advance. However, in the design or assessment of sediment-routing procedures by venting turbidity currents, the releasing schedule of the upstream reservoir is the only available upstream information to predict whether a turbidity current will form and how it will evolve thereafter. Therefore, the turbid open-channel flow model and turbidity current model are combined in this study. The water and sediment conditions predicted by the open-channel flow model provide the upstream boundary conditions for the turbidity current model. This combination also makes it possible to take the impact of the freesurface gradient into consideration when modelling the turbidity currents. Denoting the vectors of conserved variables in the open-channel flow model and turbidity current model as $\mathbf{U}_{C}$ and $\mathbf{U}_{T}$, respectively, and dividing the whole computational domain into $N$ cross-sections, a two-step calculation mode is illustrated in Figure 2 and summarized in the following steps: 


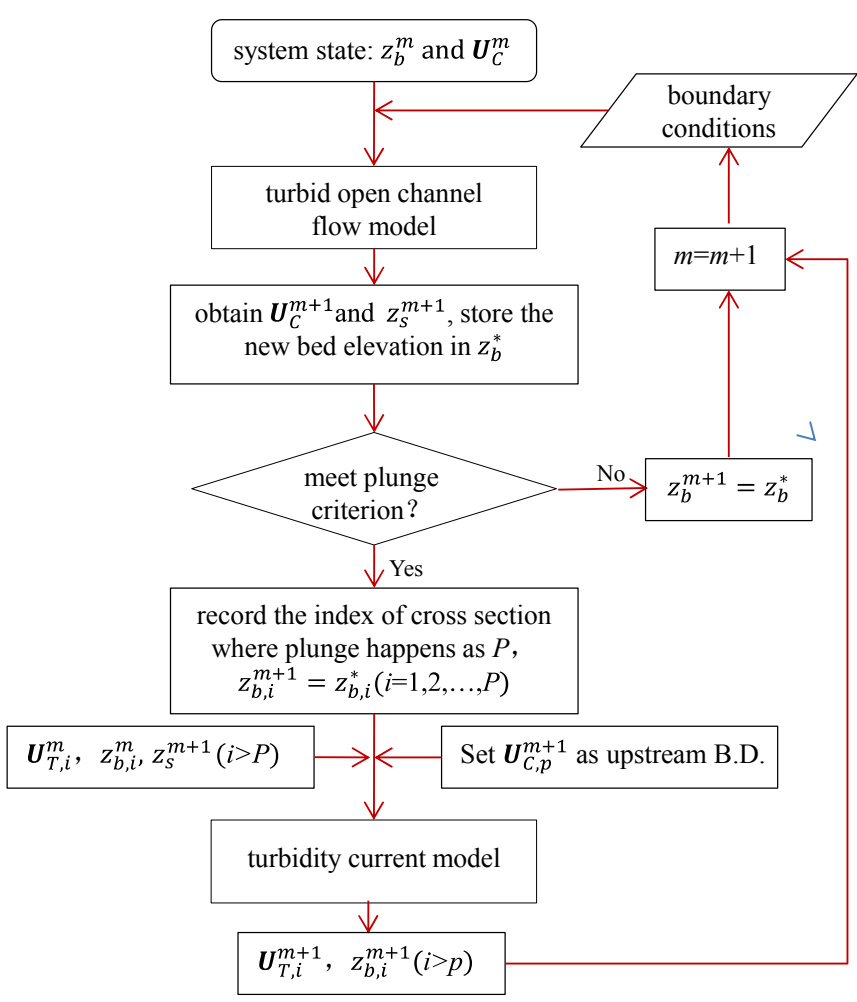

Fig. 2. Flowchart of a two-step calculation mode for coupling open channel flow and turbidity current modules.

(i) Input $z_{b}^{m}, \mathbf{U}_{C}^{m}$ and the boundary conditions at $m+1$ time step for the turbid open-channel flow model to obtain $\mathbf{U}_{C}^{m+1}$ and free-surface elevation $z_{s}^{m+1}$, and denote the updated bed elevation as $z_{b}^{*}$ temporally.

(ii) Check $\mathbf{U}_{C}^{m+1}$ at each cross-section from the upstream of a computational domain to judge if the plunge criterion is satisfied. If satisfied, the index of the cross-section is recorded as $P$, with the bed elevation of the open-channel flow reach being updated. Then the calculation mode moves on to the third step. If not, let $z_{b}^{m+1}=z_{b}^{*}$ and $m=m+1$, then the calculation mode returns to the first step.

(iii) Set $\mathbf{U}_{C, p}^{m+1}$ as the upstream boundary conditions into the turbidity current model to obtain $\mathbf{U}_{T, i}^{m+1}$ and $z_{b, i}^{m+1}(i=P+1, P+2, \ldots, N)$. Let $m=m+1$, then the calculation mode returns to the first step.

As can be seen from the above procedure, the calculations of the open-channel flow and turbidity current are coupled fully, based on the proposed flowchart. The former provides the upstream boundary conditions and free-surface elevation for the latter, while the latter updates the bed elevation shared by the former. Thus calculations in the two regions need to be executed alternately. The plunge criterion in Step (ii) is usually expressed in the form of either plunge depth (Akiyama and Stefan, 1984; Dallimore et al., 2004) or plunge Froude number (Li et al., 2011). Xia et al. (2016) established an empirical relationship between the Froude number and volumetric sediment concentration at the plunge point,

$$
F r_{p}=0.437\left(S_{v}\right)^{0.375}
$$

where the upper limit of the volumetric sediment concentration $S_{v}$ is 0.151 . This formula has been calibrated and verified with data from laboratory experiments and field measurements in the Yellow River.

\section{MODEL APPLICATION TO LABORATORY EXPERIMENTS}

The flume experiments conducted by Lee and $\mathrm{Yu}$ (1997) and Bonnecaze et al. (1993) were reproduced to verify the proposed numerical model. The experiments of Lee and Yu (1997) were designed to generate turbidity currents under a steady nonuniform condition, which were used to test the model's ability to describe the profiles of the turbidity currents, with the effect of the free-surface gradient on the model predictions being investigated. The experiments of Bonnecaze et al. (1993) focused mainly on the dynamic process of propagation and the resulting deposition of turbidity currents, which are the benchmarks for testing the means of dealing with wetting and drying fronts, and solving sediment transport in turbidity current models.

\section{Simulation of constant flux currents}

Lee and Yu (1997) conducted a series of flume experiments to study the plunge criterion and the hydraulic characteristics of the turbidity currents. The size of the flume was $20 \times 0.2 \times 0.6 \mathrm{~m}$, with a bed slope of 0.02 . The inflow discharge and its sediment concentration were kept constant during the experiments. The outflow and inflow discharges were set equal to keep the free surface stable. The suspended material used was kaolin, with a density of $2650 \mathrm{~kg} / \mathrm{m}^{3}$ and a mean particle size of $0.0068 \mathrm{~mm}$. Eighteen experimental runs were conducted and two different sections were chosen in each run to measure the velocity and concentration profiles of the turbidity currents. The inflow discharge per unit width ranged from 0.0024 to $0.0116 \mathrm{~m}^{2} / \mathrm{s}$, and the volumetric inflow concentration ranged from 0.0021 to 0.0108. Parts of these measurements were chosen to compare with the model predictions, with the experimental conditions, cross-section locations and results listed in Table 1.

Table 1. Experimental conditions and corresponding results.

\begin{tabular}{|c|c|c|c|c|c|c|c|}
\hline \multirow[b]{2}{*}{ Run } & \multicolumn{2}{|c|}{ Inflow conditions } & \multirow{2}{*}{$\frac{\text { Position }}{X_{s} / H_{p s}}$} & \multicolumn{4}{|c|}{ Results } \\
\hline & $\begin{array}{c}Q_{\text {in }} \\
\left(\mathrm{cm}^{2} / \mathrm{s}\right)\end{array}$ & $S_{v, \text { in }}\left(10^{-3}\right)$ & & $\begin{array}{c}H_{p s} \\
(\mathrm{~cm})\end{array}$ & $\begin{array}{l}X_{p s} \\
(\mathrm{~m})\end{array}$ & $\begin{array}{c}h \\
(\mathrm{~cm})\end{array}$ & $\begin{array}{c}S_{v} \\
\left(10^{-3}\right)\end{array}$ \\
\hline TC11a & 85.45 & 3.88 & 8.07 & 14.49 & 10.13 & 11.01 & 3.52 \\
\hline $\mathrm{TC} 17 \mathrm{~b}$ & 96.47 & 7.81 & 40.12 & 11.44 & 8.71 & 9.73 & 6.52 \\
\hline $\mathrm{TC} 3 \mathrm{~b}$ & 42.25 & 3.63 & 69.58 & 8.91 & 7.10 & 7.86 & 2.92 \\
\hline $\mathrm{TC} 2 \mathrm{~b}$ & 24.76 & 7.16 & 138.43 & 5.62 & 5.52 & 6.20 & 4.94 \\
\hline
\end{tabular}

$Q_{i n}$ is the inflow discharge per unit width; $S_{v, i n}$ is the inflow sediment concentration; $X_{p s}$ is the distance between the stable plunge point and the flume entrance; $H_{p s}$ is the plunge depth; $X_{s}$ is the distance from the stable plunge point, $h$ and $S_{v}$ are the corresponding current thickness and sediment concentration. 
The time and spatial steps adopted in the simulation were $0.1 \mathrm{~s}$ and $0.25 \mathrm{~m}$, respectively, with a Manning roughness coefficient of $n=0.02$ being used. The longitudinal variation in the dimensionless thickness of the turbidity current can be represented by plotting $h / H_{p s}$ versus $X_{s} / H_{p s}$, as shown in Figure 3a. In a region close to the plunge point $\left(0<X_{s} / H_{p s}<15\right.$, according to Lee and $\mathrm{Yu}(1997))$ the thickness of the turbidity current decreased longitudinally. Beyond this region, the current thickness increased gradually owing to the water entrainment. Therefore, Figure $3 \mathrm{a}$ shows that the model predictions agree well with the experimental results. By comparison, the calculated results with the hypothesis of a horizontal free surface that neglects the third term on the RHS of Eq. (4), are also presented in Figure 3, with the difference between the measured and calculated results being obvious. Figure $3 b$ shows the comparison between the measured and calculated sediment concentrations. The maximum relative errors of the calculated current thickness are $8.7 \%$ and $27.5 \%$, with and without considering the free-surface gradient, respectively. The maximum relative errors of the calculated sediment concentrations are $12.6 \%$ and $20.5 \%$ for these two scenarios. It is clear that the free-surface gradient had a significant influence on accuracy when modelling turbidity currents. A coupled solution to the calculations of open-channel flow and turbidity current can help to provide the necessary free-surface elevation.

According to the experimental observations of Lee and $\mathrm{Yu}$ (1997), the plunge point was not stable at the formation stage. As it migrated from the incipient plunge location to the stable location, the plunge depth increased, with the densimetric Froude number decreasing accordingly. This migration only took a short period of time (between 1.9 to 3.2 minutes), as compared with the duration of the turbidity current event in the reservoir. In practice, more attention is paid to the migration of the plunge point due to the variation of inflow conditions or the reservoir operation when modelling reservoir turbidity currents. Thus, the incipient plunge location is not considered in this study, and Eq. (19) is used to determine the stable plunge location. In this test case, the maximum error of predictions for the plunge positions $X_{p s}$ in Table 1 is $0.91 \mathrm{~m}$, which is within four spatial steps.

\section{Simulation of constant volume currents}

Bonnecaze et al. (1993) observed the propagation of turbidity currents induced by a sudden release of a constant volume of water and sediment mixture in a closed flume with no bed slope, which is also known as the "lock-exchange experiment". The size of the flume was $10 \mathrm{~m} \times 0.26 \mathrm{~m} \times 0.48 \mathrm{~m}$ and a gate was placed $15 \mathrm{~cm}$ from the endwall (see Figure 4). The depth of the water-sediment mixture and clear water on each side of the gate was $15 \mathrm{~cm}$. Several runs were conducted, with different initial sediment concentrations and sediment particles of different diameters. All particles had a density of $3217 \mathrm{~kg} / \mathrm{m}^{3}$.

Figure 5a illustrates the temporal evolution of the propagation length of turbidity currents in two experimental runs. The amounts of sediment in the mixture were both $400 \mathrm{~g}$, and the particle diameters were $9 \mu \mathrm{m}$ and $53 \mu \mathrm{m}$, respectively. The adopted time step $\Delta t$ was $0.02 \mathrm{~s}$ in the model. Sediments with larger particle size settle faster, leading to a more rapid decrease in the reduced gravity, and finally, a shorter propagating distance. The simulations showed this propagation trend accurately. In the first 20 seconds, the predicted propagating speed in the simulation of current with $53 \mu \mathrm{m}$ particle diameter was slightly faster than the measured value. After $20 \mathrm{~s}$, the calcu-
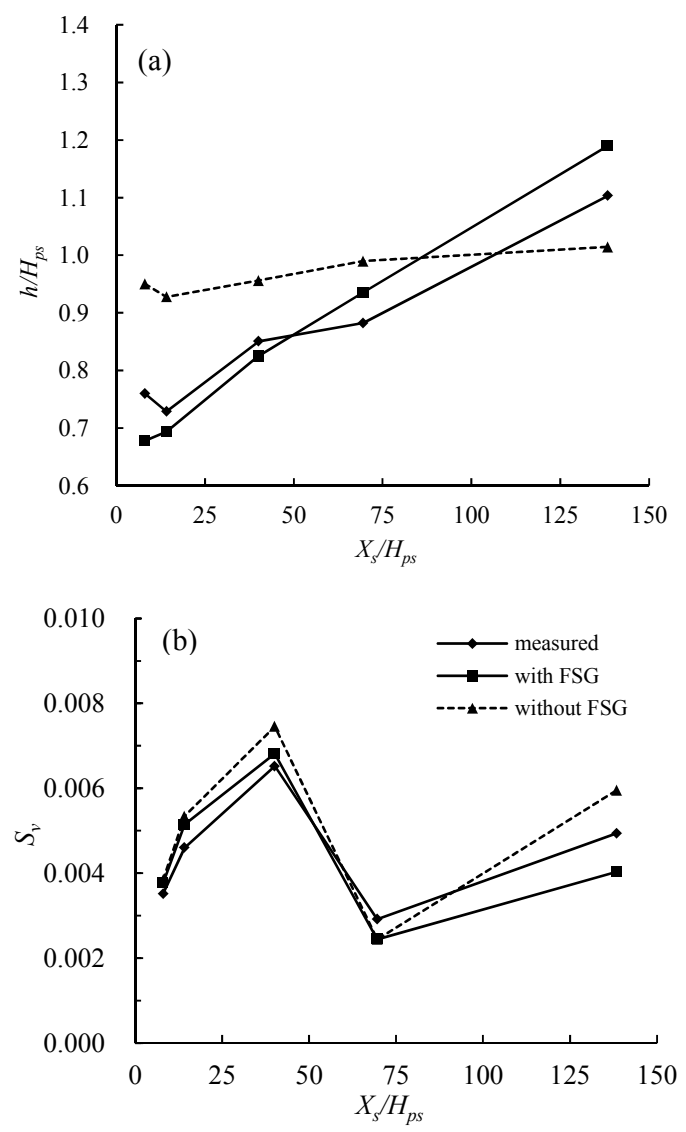

Fig. 3. Numerical results with or without the free surface gradient (FSG) term being included compared with measured data: (a) dimensionless current thickness; and (b) volumetric sediment concentration.

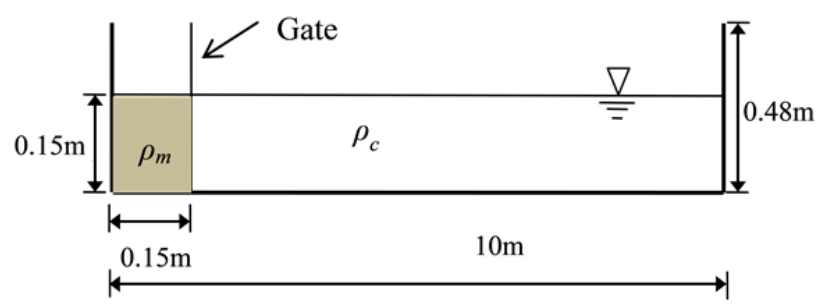

Fig. 4. Schematic view of the flume used in lock-exchange experiment.

lated speed decreased gradually and became almost the same as the measured value. The simulation for the current with $9 \mu \mathrm{m}$ particle diameter appeared to show a similar process. In order to track the current front, two kinds of methods are usually adopted. One is to impose a front velocity condition to determine the propagating length of the turbidity current (Bonnecaze et al., 1995; La Rocca et al., 2008). For example, in the work of Bonnecaze et al. (1993), they used the experimentally determined Froude number at the front (Huppert and Simpson, 1980) to specify the downstream velocity condition, and a coordinate transformation was required to account for the time dependency of the computational domain. The other method is to adopt a Riemann solver which admits a wet-dry interface problem (Bradford and Katopodes, 1999a; Toro, 2001) to pursue the correct evaluation of the flux between wet and dry cells, as adopted in this proposed model. With this method, the downstream boundary can be simply treated as an open boundary. 

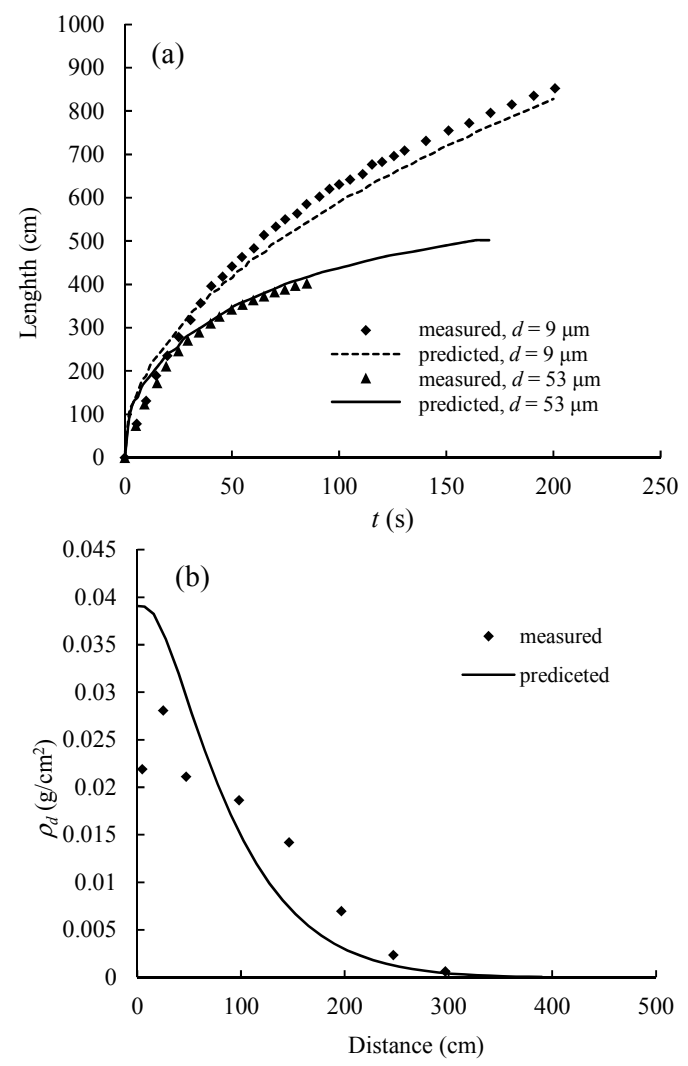

Fig. 5. Numerical results compared with the measured data: (a) temporal evolution of propagation length; (b) longitudinal variation of deposit areal density.

The areal density of the deposit $\rho_{d}$ is defined as the mass of deposit on the unit area on the bed, which reflects the bed deformation caused by the turbidity currents. Figure 5 b shows the comparison between the calculated and measured $\rho_{d}$ for the experiment of $100 \mathrm{~g}$ sediment with $53 \mu \mathrm{m}$ diameter. In the first $80 \mathrm{~cm}$ of the flume the value of $\rho_{d}$ was predicted to be larger than the measured value. This discrepancy might be attributed to the man-made turbulent state in the whole body of the mixture, in order to keep the sediment suspended before withdrawing the gate. Thus, in the early propagating stage, the actual settling flux of sediment was smaller than the flux calculated using the model based on a vertical sediment concentration profile under an equilibrium state. Since the amount of released sediment was fixed, less sediment would be transported downstream, leading to a smaller $\rho_{d}$ in the rest part of the flume.

\section{MODELLING OF TURBIDITY CURRENT EVENTS IN THE SANMENXIA RESERVOIR}

The Sanmenixia Reservoir is located on the lower part of the Middle Yellow River, in China. The drainage area above the dam amounts to $688,400 \mathrm{~km}^{2}$, which is $92 \%$ of the total drainage area of the Yellow River (Morris and Fan, 1998). Before the construction of the downstream Xiaolangdi Reservoir, it undertook the major task of flood control in the Lower Yellow River. Since its impoundment in September 1960, the reservoir had been experiencing severe sedimentation. In order to mitigate the rate of storage loss and avoid an increasing risk of flooding, the reservoir had undergone two rounds of reconstruction and some major adjustments in the operation mode. During the period 1961 to 1964 , twenty two turbidity current events were observed, with lots of field measurements recorded.

Two turbidity current events occurring in the Sanmenxia Reservoir, characterized by unsteady inflows caused by hyperconcentrated sediment-laden floods, were simulated to validate the capability of the model to solve large-scale prototype problems. The study domain covered the area from the upstream hydrometric station at Tongguan to the dam site of the Samenxia Reservoir, with a $112.5 \mathrm{~km}$ long reach, as shown in Figure 6. In the study reach, 34 cross-sectional profiles were surveyed in May 1962, and were numbered in a decreasing order from upstream to downstream. In addition, three cross-sectional profiles were interpolated in local sub-reaches, with the channel widths varying greatly. These cross-sectional profiles were set as the initial boundary condition, with the distances between two consecutive sections varying between 0.8 and $5.5 \mathrm{~km}$.

These two turbidity current events were observed from 15 July to 5 August, 1962. The hydrographs of discharge and sediment concentration at Tongguan were used as the upstream conditions, as shown in Figure 7a. In the step of computing the open-channel flow, the water level at HY1 (the nearest section to the dam site) and the releasing discharge of the reservoir were used as the downstream conditions, as shown in Figure $7 \mathrm{~b}$. The gradation and dry-bulk density of bed material at each section were interpolated using the measured data at several sections.

In the step for computing the turbidity current, no constraints were imposed on the downstream boundary before the current reached the dam site. After the arrival of the current, its outflow discharge was dependent on the size and elevation of bottom outlets. Rare methodologies can be found to set suitable boundary conditions to deal with this situation in depth-averaged numerical models. In the proposed model, the velocity profile

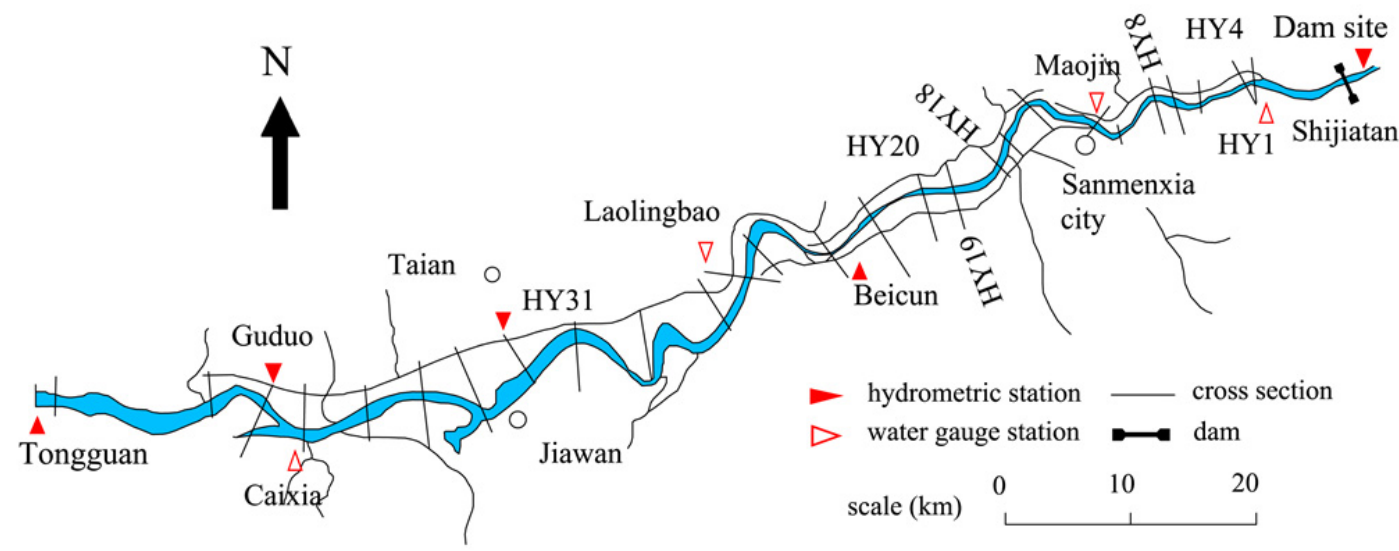

Fig. 6. Plan view of the Sanmenxia Reservoir. 

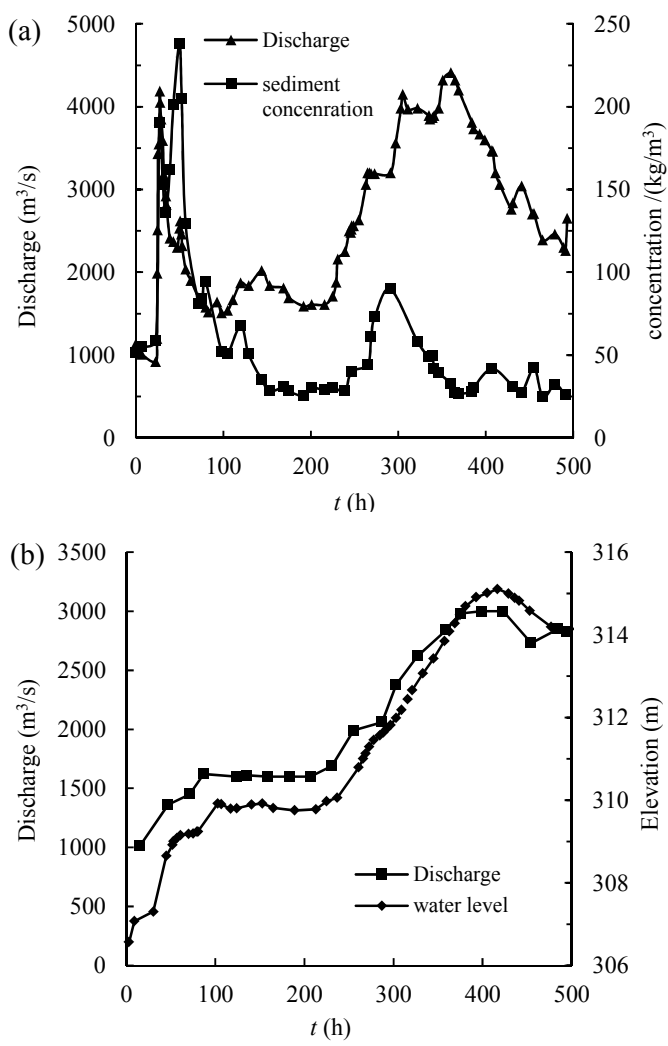

Fig. 7. Boundary conditions for the open channel flow calculation: (a) inflow discharge and sediment concentration; (b) outflow discharge and water level.

is assumed to be uniform in the upper (above the interface) and lower (below the interface) parts of the withdrawal layer (Fan, 2008). Then it can be derived that the ratio of the outflow discharge of the turbidity current to the total releasing discharge is equal to the ratio of the thickness of turbidity current near the dam $h_{T}$ to the thickness of withdrawal layer $H_{\mathrm{s}}$, where $H_{\mathrm{s}}=$ $h_{0}+h_{L}, h_{0}=$ bottom outlet height, and $h_{L}=$ limiting height of aspiration (Figure 8). In this model, $h_{L}$ was determined with the formula suggested by Fan (2007):

$h_{L}=\frac{0.9}{\left(g^{\prime} / Q_{0}^{2}\right)^{1 / 5}}$

where $Q_{0}$ is the discharge through a single outlet.

\section{Model calibration}

The first turbidity current event started at 09:00 on 15 July (i.e., $t=0 \mathrm{~h}$ in Fig. 7) and lasted 140 hours until 05:00 on 21 July, and the time step $\Delta t$ of $10 \mathrm{~s}$ was used in this calibration process. The operation principle of the reservoir changed from the previous mode of storing water and retaining sediment to the mode of flood detention and sluicing silt in this year. Based on this principle, all the bottom outlets of the dam were open during the event. It also needs to be noted that no change of rheological property was considered here for hyperconcentrated floods in the Yellow River, with the current still being regarded as a kind of turbulent Newtonian flow (Li et al., 2014), although the peak concentration was over $200 \mathrm{~kg} / \mathrm{m}^{3}$, as shown in Fig. 7(a)

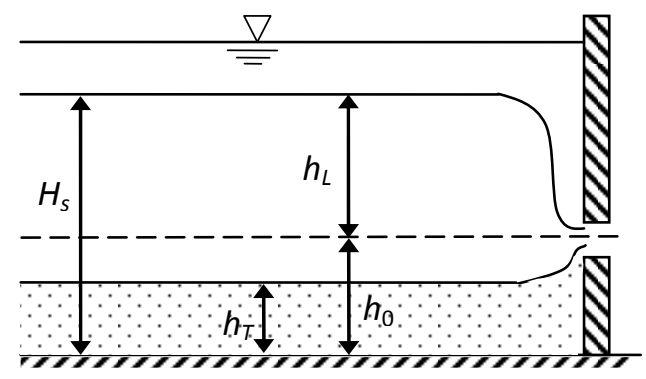

Fig. 8. Sketch of the withdrawal layer.

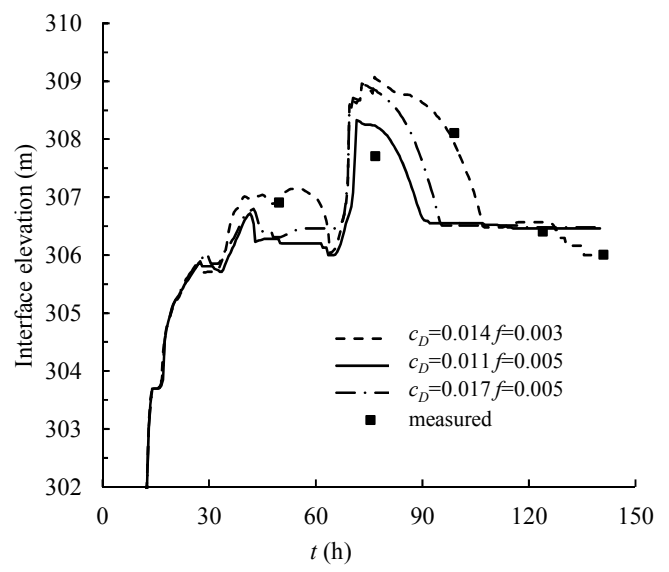

Fig. 9. Comparison of the calculated and measured interface elevations at HY8.

Figure 9 illustrates the elevations of the interface between the turbid and clear water, calculated using different bed drag coefficients and interface friction coefficients at the crosssection of HY8 $(9.1 \mathrm{~km}$ upstream of the dam). It can be seen that an increase in the friction parameters would delay the peak interface level, and would influence the subsequent evolution significantly. In the case of $c_{D}=0.014$ and $f=0.003$ used in the simulation, the temporal variations in the free-surface and interface elevations, at the HY4 and HY1 sections, are shown in Figure 10. It can be seen in Figure 10 that the prediction of the interface elevation is more difficult than the prediction of the free-surface elevation, while the calculated processes in general agrees with the measurements. In Figure 10b, the calculated interface elevation reached the free-surface elevation at $t=$ $40 \mathrm{~h}$, and the observation record also mentioned that the water near the dam once became turbid during the first event, i.e., the occurrence of a muddy lake (Toniolo et al., 2007). The temporal variations in sediment concentrations at these two sections are shown in Figure 11. The peak of the predicted sediment concentration appeared when the predicted interface elevation rose sharply, which indicates that the sediment concentration at the front of the turbidity current was very high.

The plunge point determined by Eq. (19) was located at HY18 at the beginning of the simulation (see Figure 12(a)), and migrated upstream to HY19 after one hour. However, according to the observation of the longitudinal profile in the computed domain, the interface and the free surface were at the same level and did not separate until HY14, which complied with the recorded location where the plunge occurred. To predict the arrival times of the turbidity currents at each section, a morphodynamic model needs to identify the location of the plunge point correctly, and to calculate the propagating speed accurately. From Figure 9 and 10, the predicted hydrograph of the interface elevation went through the first data point at HY8 and 

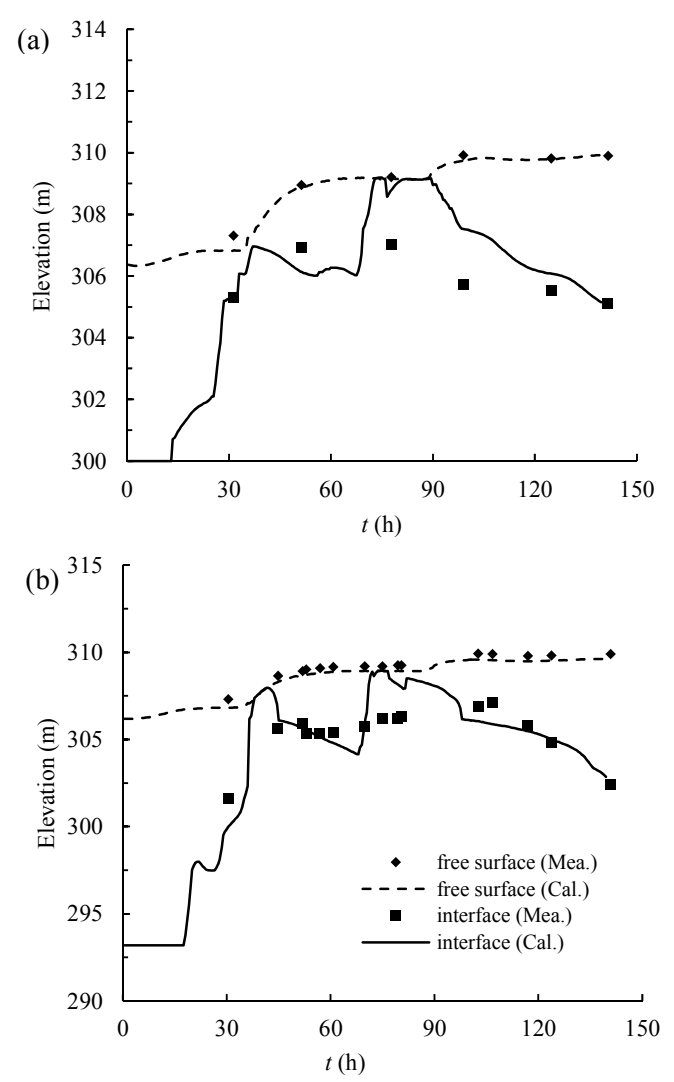

Fig. 10. Temporal variations of free surface and interface elevations at: (a) HY4; (b) HY1.

HY4, and missed a little from the first data point at HY1, which demonstrated the applicability of the plunge criterion and the validity of the "dry" bed methodology used in the proposed model. In Figure 12(b), the current just arrived at the downstream end of the topset bed and began to enter the reach with a suddenly increased slope in front of the dam. At $t=16.8 \mathrm{~h}$, the current reached the dam site (Figure 12c). The average propagating speed of the current was about $0.4 \mathrm{~m} / \mathrm{s}$ from its formation to its arrival at the dam. With the interface rising gradually, the muddy lake formed, as shown in Figure 12d. Figure $12 \mathrm{e}$ shows the terminal state of this simulation, in which the interface elevation in front of the dam dropped back to $302 \mathrm{~m}$, and the free surface rose by $3.2 \mathrm{~m}$ from its initial level.

The venting efficiency of the turbidity currents is of interest in reservoir sediment management. Most previous studies attempted to establish empirical relationships between the venting efficiency and the geometric parameters of the reservoir and the inflow and outflow conditions (Morris and Fan, 1998). With the detailed simulation results provided by the proposed morphodynamic model, the calculated discharge and sediment concentration of the turbidity current were used readily to estimate the venting efficiency. Considering the period during which the interface was higher than the bottom outlets $(300 \mathrm{~m})$ as the turbidity outflow stage, $24.8 \times 10^{6} \mathrm{t}$ sediment was released over this period, according to the average daily sediment transport rate through the dam. The amount of delivered sediment at the same stage was predicted to be equal to $28.6 \times 10^{6} \mathrm{t}$, with a relative error of $15.3 \%$. The calculated and measured sediment delivery ratios were $10.2 \%$ and $8.8 \%$, respectively. The predicted sediment transport rate at HY1 $(1 \mathrm{~km}$ upstream of the dam) was used to calculate the amount of sediment delivered in the outflow, which might be a main contributor to the discrepancy.
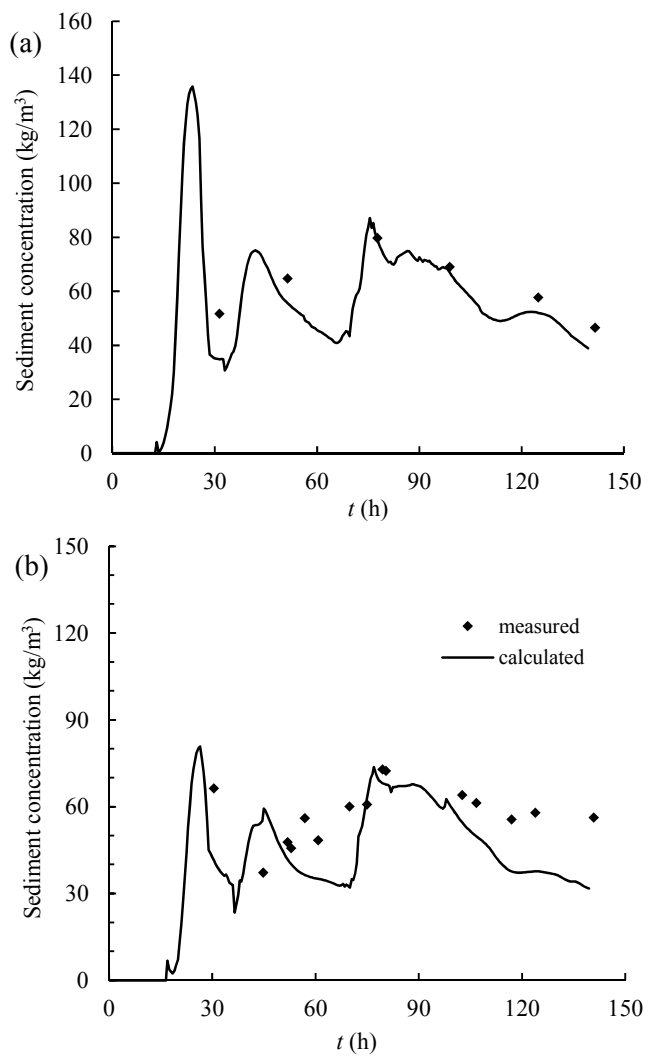

Fig. 11. Temporal variations of sediment concentrations at: (a) HY4; (b) HY1.

\section{Model verification}

The second turbidity current event was observed on 26 July, and this event was simulated using the proposed model, based on the same parameters in the calibration case. In the initial operation period of the Sanmenxia Reservoir, intensive erosion and deposition processes occurred in the study area. Comparison of the topographic data measured in May and August, 1962, shows that the maximum scour depth upstream was about $9 \mathrm{~m}$, and the maximum deposition depth downstream was about $7 \mathrm{~m}$. As for the longitudinal channel profile, the topset slope became milder and the bed elevation near the dam rose by about $1.1 \mathrm{~m}$. All these changes might have significant impacts on the current propagation and the discharge capacity of the bottom outlets. Therefore, the initial cross-sectional profiles in the verification case were replaced with the measured data in August, although the time interval between the two turbidity current events was relatively short.

The plunge position was predicted to occur around HY20, which was consistent with the field observation. An accurate prediction of the plunge position depends on the simulation of the open-channel flow in the coupled model. Figure 13 shows the calculated temporal variations in the discharge and sediment concentration at HY31, which was located in the open-channel flow reach. The time $t=0 \mathrm{~h}$ corresponds to 02:00 on $23 \mathrm{July}$. The wave pattern and speed of the flood peak were predicted to agree closely with the measurements. The peak discharge and concentration were predicted to be equal to $4461 \mathrm{~m}^{3} / \mathrm{s}$ and 83 $\mathrm{kg} / \mathrm{m}^{3}$, respectively, with corresponding measured values of $4150 \mathrm{~m}^{3} / \mathrm{s}$ and $104 \mathrm{~kg} / \mathrm{m}^{3}$.

Figure 14 shows a comparison of the measured and predicted free-surface and interface elevations at three different cross-sections. It was found that the prediction accuracy for the 

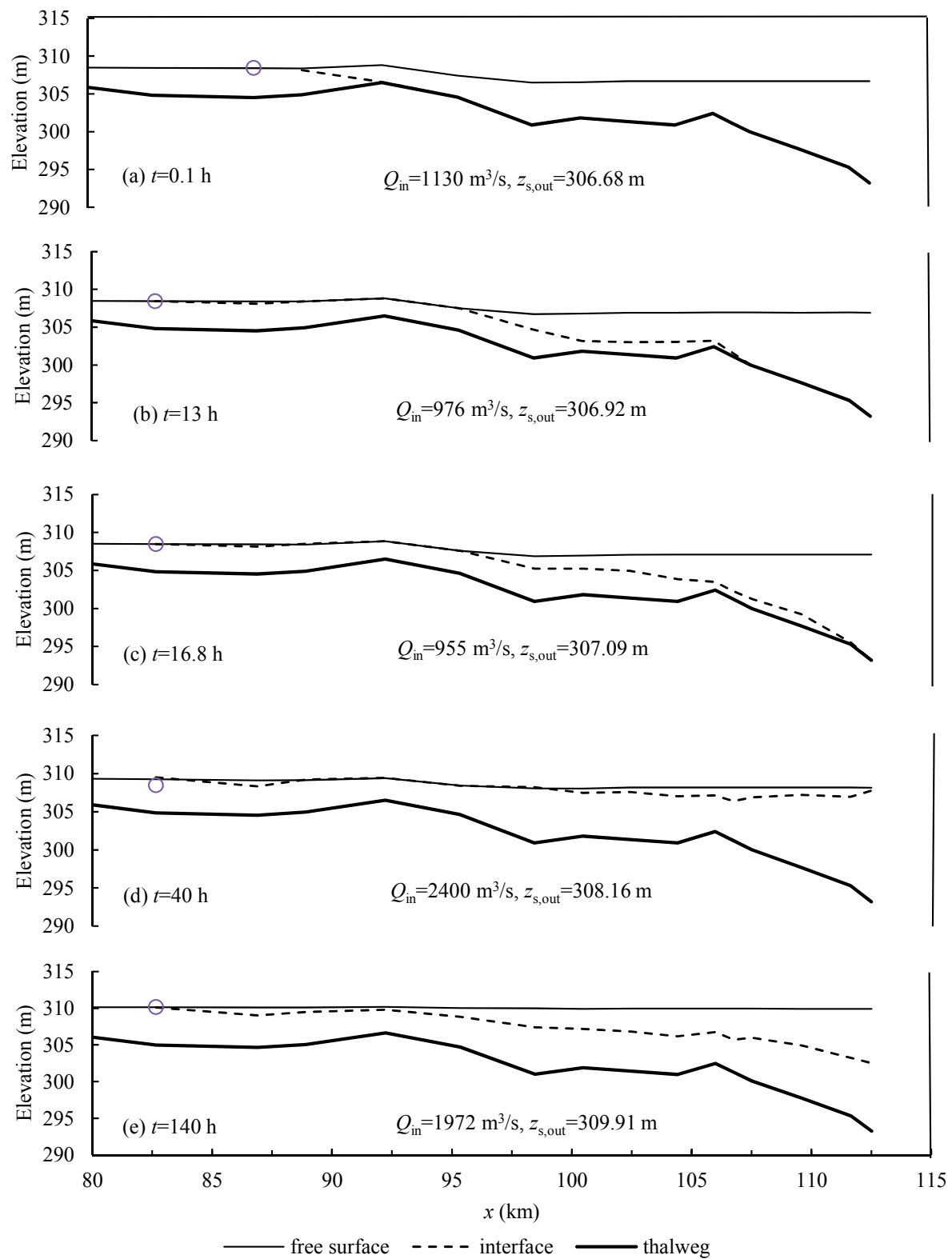

Fig. 12. Longitudinal profiles of free surface, interface and river bed at different times. $Q_{\text {in }}$ is the inflow discharge and $z_{\mathrm{s} \text {, out }}$ is the water level at the dam site.

free-surface elevation was much better than that of the interface elevation. The maximum prediction error of free-surface elevation is $-0.69 \mathrm{~m}$, which occurs at HY19 during the water-level recession. If the magnitude of the water-level variation in the reservoir is rather large, a traditional model may be inapplicable to simulate the turbidity current processes accompanied by considerable reservoir impounding and releasing, when neglecting the open-channel flow reach, or assuming a horizontal free surface. From Figure 14b, it can be seen that the model predicted well the interface rising period. In contrast, the predictions in the recessing period were unsatisfactory, as shown in Figure $14 \mathrm{a}$ and $14 \mathrm{c}$. However, the measured data contained many uncertainties because of the disadvantageous field conditions or the limitations of measuring method. In addition, the measured interface elevation was highly sensitive to the threshold sediment concentration for identifying the surface position of the underflow (Hu et al., 2012).

In Figure 14c, the plateau on the time series of interface elevation between $t=52$ and $100 \mathrm{~h}$ was owing to the downstream conditions used to consider the aspiration effect. The time to reach the flood peak was much longer in the second event (see Figure 7a) and the peak sediment concentration of the inflow was much smaller. Therefore, the interface near the dam rose much slower than in the first event and no muddy lake formed. The actual amount of sediment delivered during the turbidity outflow stage was $23.7 \times 10^{6} \mathrm{t}$, and the model prediction was $28.8 \times 10^{6} \mathrm{t}$, with a relative error of $21.1 \%$. The sediment delivery ratios calculated with the measured data and simulation results are $24.9 \%$ and $30.3 \%$, respectively. The increased sediment delivery ratio was attributed mainly to the larger mean discharge of the total release, $2461 \mathrm{~m}^{3} / \mathrm{s}$, as compared with $1485 \mathrm{~m}^{3} / \mathrm{s}$ in the first event. The sediment delivery ratio was overestimated further than that of the calibration case, which might be explained by the prolonged turbidity outflow stage in the simulation, as a result of the underestimated falling speed of the interface during recession near the dam. 

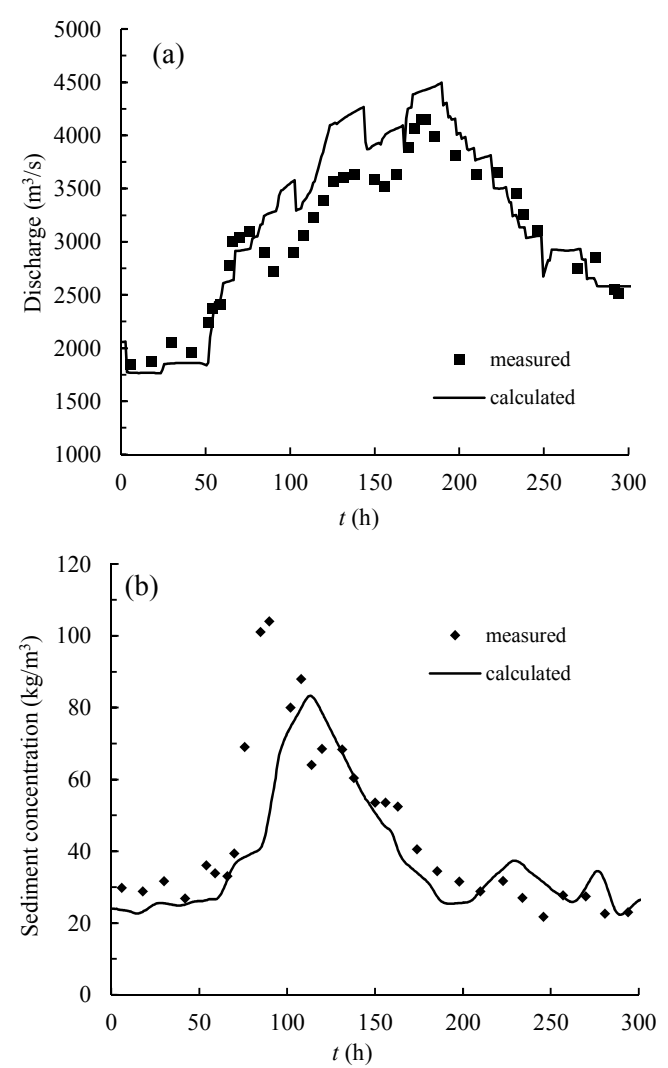

Fig. 13. Comparison of measured data and numerical solutions to (a) discharge and (b) sediment concentration at HY31.

\section{CONCLUSIONS}

A morphodynamic model for open-channel flows and turbidity currents in a reservoir was proposed. The governing equations were derived based on irregular cross-sectional geometry, and solved simultaneously with the processes of sediment transport and bed deformation, with their feedback impacts on the currents being incorporated. The turbidity current model was coupled with the open-channel flow model to extend the upstream boundary to the location where the water and sediment conditions are controllable or obtainable. Determining the location of plunge point dynamically is important because in practice the location can shift upstream or downstream, as a result of the unsteady inflow during a high sediment-laden flood in a reservoir. The model was verified against two laboratory experiments and applied to a prototype study on turbidity current events occurring in the Sanmenxia Reservoir. The conclusions drawn from these tests include the following:

(i) Incorporating the free-surface gradient term in the momentum equation produces better prediction in the constant flux test, while the neglect of this term leads to a much more uniform turbidity current thickness. The Riemann solver admitting wet-dry interface waves was demonstrated to be capable of treating the front advance of the turbidity currents, and the size of the sediment particle had significant impacts on the propagating speed.

(ii) Turbidity currents in reservoirs can be simulated from the formation to the recession, by coupling the open-channel flow module and turbidity current module. Predicting the elevation of the interface between the underflow and the upper clear water is more challenging than predicting the sediment concetration or the arrival time, especially for the recession stage during which the evolution of the currents is affected strongly
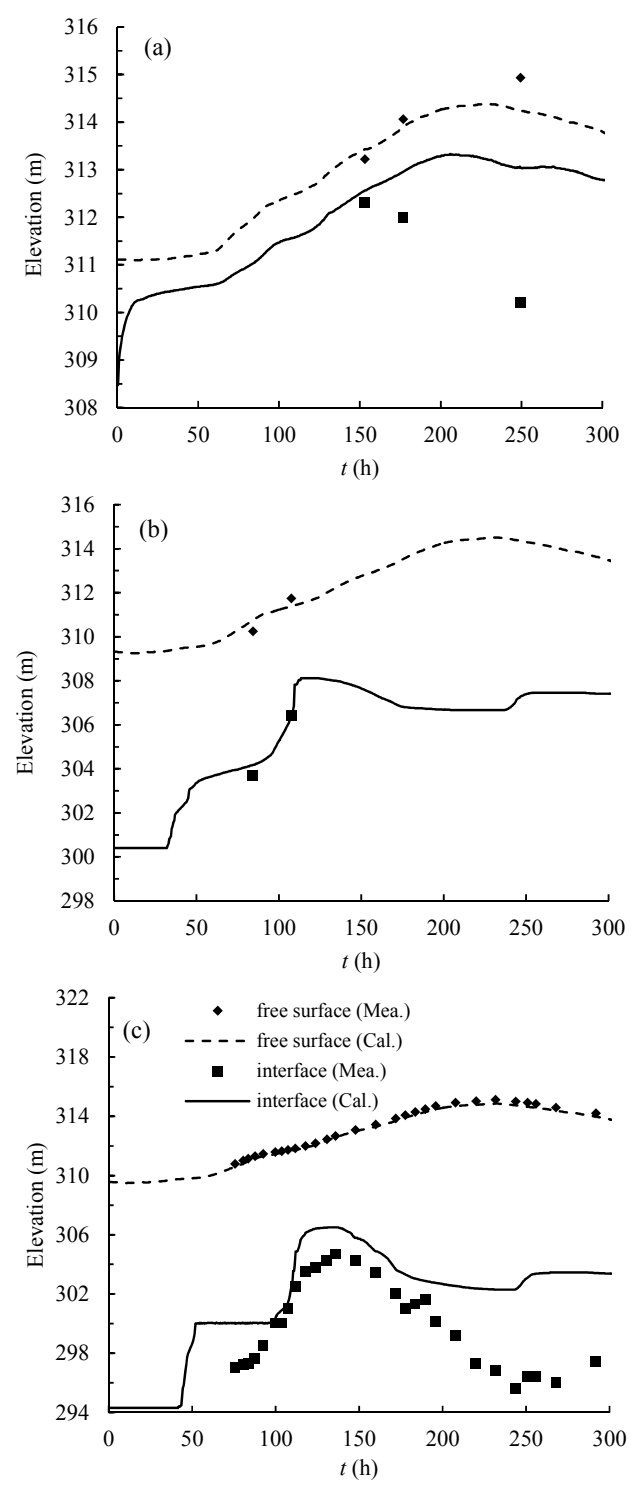

Fig. 14. Temporal variations of free surface and interface elevations at: (a) HY19; (b) HY4; (c) HY1.

by the constrained outflow condition. Adopting the aspiration layer theory is a preliminary attempt to determine the outflow discharges of the turbidity currents through a dam. Uncertainties may come from the model itself, such as the empirical relationships evaluating the clear water and bed sediment entrainments, and also the sparsely measured cross-sections or the sampling method for determining the interface.

(iii) The sediment delivery ratio can vary greatly, even for two subsequent turbidity current events in one flood season in a reservoir. The estimation of the sediment delivery ratio is closely related to the predicted evolution process of the surface elevation of the turbid water in front of the dam.

Acknowledgements. This work was supported by the National Natural Science Foundation of China (Grant Nos. 51379156 and 51179072), and the Open Research Fund Program of the Key Laboratory of Yellow River Sediment, MWR (Grant No. 201306). It was also partly supported by the Scientific Special Expenditure for Nonprofit Public Industry from the Chinese Ministry of Water Resources (Grant No. 201401023) and the research program from the Yellow River Institute of Hydraulic Research (Grant No. HKY-JBYW-2014-02). 


\section{REFERENCES}

Akiyama, J., Stefan, H.G., 1984. Plunging flow into a reservoir: theory. Journal of Hydraulic Engineering, 110, 4, 484- 499.

Bonnecaze, R.T., Huppert, H.E., Lister, J.R., 1993. Particle-driven gravity currents. Journal of Fluid Mechanics, 250, 339-369.

Bonnecaze, R.T., Hallworth, M.A., Huppert, H.E., Lister, J.R., 1995. Axisymmetric particle-driven gravity currents. Journal of Fluid Mechanics, 294, 93-121.

Bournet, P.E., Dartus, D., Tassin, B., Vincon-Leite, B., 1999. Numerical investigation of plunging density current. Journal of Hydraulic Engineering, 125, 6, 584-594.

Bradford, S.F., Katopodes, N.D., 1999a. Hydrodynamics of turbid underflows. I: Formulation and numerical analysis. Journal of Hydraulic Engineering, 125, 10, 1006-1015.

Bradford, S.F., Katopodes, N.D., 1999b. Hydrodynamics of turbid underflows. II: Aggradation, avulsion, and channelization. Journal of Hydraulic Engineering, 125, 10, 1016-1028.

Cantero, M.I., Balachandar, S., Cantelli, A., Pirmez, C., Parker, G., 2009. Turbidity current with a roof: direct numerical simulation of self-stratified turbulent channel flow driven by suspended sediment. Journal of Geophysical Research: Oceans, 114, C3, 126-138.

Cao, Z., Li, J., Pender, G., Liu, Q., 2015. Whole-process modeling of reservoir turbidity currents by a double layeraveraged model. Journal of Hydraulic Engineering, 141, 2, 04014069.

Chen, J.C., 1980. Studies on Gravitational Spreading Currents. $\mathrm{PhD}$ thesis. California Institute of Technology, The city is Pasadena, California.

Dallimore, C.J., Imberger, J., Hodges, B.R., 2004. Modeling a plunging underflow. Journal of Hydraulic Engineering, 130, $11,1068-1076$.

De Cesare, G., Boillat, J., Schleiss, A.J., 2006. Circulation in stratified lakes due to flood-induced turbidity currents. Journal of Hydraulic Engineering, 132, 11, 1508-1517.

Fan, J., 2008. Stratified flow through outlets. Journal of HydroEnvironment Research, 2, 1, 3-18.

Fan, J., 2007. Analysis on turbid density current outflow through outlets. Journal of Chinese Hydraulic Engineering, 38, 9, 1073-1079. (In Chinese.)

Fan, J., Morris, G.L., 1992. Reservoir sedimentation I: Delta and density current deposits. Journal of Hydraulic Engineering, 118, 3, 354-369.

Hoult, D.P., 1972. Oil spreading on the sea. Annual Review of Fluid Mechanics, 4, 1, 341-368.

Hu, P., Cao, Z., 2009. Fully coupled mathematical modeling of turbidity currents over erodible bed. Advances in Water Resources, 32, 1, 1-15.

Hu, P., Cao, Z., Pender, G., Tan, G., 2012. Numerical modeling of turbidity currents in the Xiaolangdi reservoir, Yellow River, China. Journal of Hydrology, 464, 41-53.

Huang, H., Imran, J., Pirmez, C., 2008. Numerical study of turbidity currents with sudden-release and sustained-inflow mechanisms. Journal of Hydraulic Engineering, 134, 9, 1199-1209.

Huppert, H.E., 2006. Gravity currents: a personal perspective. Journal of Fluid Mechanics, 554, 299-322.

Huppert, H.E., Simpson, J.E., 1980. The slumping of gravity currents. Journal of Fluid Mechanics, 99, 4, 785-799.

La Rocca, M., Adduce, C., Sciortino, G., Pinzon, A.B., 2008. Experimental and numerical simulation of three-dimensional gravity currents on smooth and rough bottom. Physics of Fluids, 20, 10, 106603.
Lee, H.Y., Yu, W.S., 1997. Experimental study of reservoir turbidity current. Journal of Hydraulic Engineering, 123, 6, 520-528.

Li, Y., Zhang, J., Ma, H., 2011. Analytical Froude number solution for reservoir density inflows. Journal of Hydraulic Engineering, 49, 5, 693-696.

Li, W., van Maren, D.S., Wang, Z., de Vriend, H.J., Wu, B., 2014. Peak discharge increase in hyperconcentrated floods. Advances in Water Resources, 67, 65-77.

Morris, G.L., Fan, J., 1998. Reservoir Sedimentation Handbook: Design and Management of Dams, Reservoirs, and Watersheds for Sustainable Use. McGraw Hill Professional, New York.

Pantin, H.M., 1979. Interaction between velocity and effective density in turbidity flow: phase-plane analysis, with criteria for autosuspension. Marine Geology, 31, 59-99.

Parker, G., Garcia, M., Fukushima, Y., Yu, W., 1987. Experiments on turbidity currents over an erodible bed. Journal of Hydraulic Research, 25, 1, 123-147.

Parker, G., Fukushima, Y., Pantin, H.M., 1986. Selfaccelerating turbidity currents. Journal of Fluid Mechanics, 171, 145-181.

Ruo, A.C., Chen, F., 2007. Modified shallow water equations for inviscid gravity currents. Physical Review E, 75, 2, 026302.

Sequeiros, O.E., Cantero, M.I., Garcia, M.H., 2009. Sediment management by jets and turbidity currents with application to a reservoir for flood and pollution control in Chicago, Illinois. Journal of Hydraulic Research, 47, 3, 340-348.

Tan, W.Y., 1992. Shallow Water Hydrodynamics. Elsevier, New York.

Toniolo, H., Parker, G., Voller, V., 2007. Role of ponded turbidity currents in reservoir trap efficiency. Journal of Hydraulic Engineering, 133, 6, 579-595.

Toro, E.F., 2001. Shock-Capturing Methods for Free-Surface Shallow Flows. Wiley, Chichester, England.

Toro, E.F., 2009. Riemann Solvers and Numerical Methods for Fluid Dynamics. Springer, Berlin.

Wu, W.M., Wang, S.S.Y., 2007. One-dimensional modeling of dam-break flow over movable beds. Journal of Hydraulic Engineering, 133, 1, 48-58.

Xia, J., Lin, B., Falconer, R.A., Wang, G., 2010. Modelling dam-break flows over mobile beds using a 2D coupled approach. Advances in Water Resources, 33, 2, 171-183.

Xia, J., Li, T., Wang, Z., Zhang, J., 2016. Improved criterion for the plunge of reservoir turbidity currents. Proceedings of the Institution of Civil Engineers-Water Management. DOI: 10.1680/jwama.15.00046

Xie, J., 1990. River Simulation. Water Conservancy and Electric Power Press, Beijing. (In Chinese.)

Ying, X., Khan, A.A., Wang, S.S., 2004. Upwind conservative scheme for the Saint Venant equations. Journal of Hydraulic Engineering, 130, 10, 977-987.

Zhang, S., Duan, J.G., 2011. 1D finite volume model of unsteady flow over mobile bed. J. Hydrol., 405, 1, 57-68.

Zhang, R.J., Xie, J.H., 1993. Sedimentation Research in China. Water and Power Press, Beijing, China.

Zhang, H., Huang, Y., Zhao, L., Jiang, E., 2002. A mathematical model for unsteady sediment transport in the lower Yellow River. I: model equations and numerical method. Advances in Water Science, 13, 3, 265-270. (In Chinese.)

Received 19 May 2016 Accepted 26 July 2016 